\title{
Experiences of a Dilated Cardiomyopathy Patient Suffering to Maintain Life Partnership Based on Margaret Newman's Theory
}

\author{
Ryoko Igarashi \\ School of Nursing, Faculty of Medicine Tokyo Medical University, Tokyo, Japan \\ Email: igaryo@tokyo-med.ac.jp
}

How to cite this paper: Igarashi, R. (2019) Experiences of a Dilated Cardiomyopathy Patient Suffering to Maintain Life Partnership Based on Margaret Newman's Theory. Open Journal of Nursing, 9, 31-40. https://doi.org/10.4236/ojn.2019.91004

Received: November 30, 2018

Accepted: January 18, 2019

Published: January 21, 2019

Copyright $\odot 2019$ by author(s) and Scientific Research Publishing Inc. This work is licensed under the Creative Commons Attribution International License (CC BY 4.0).

http://creativecommons.org/licenses/by/4.0/

\begin{abstract}
Background: Dilated cardiomyopathy is a refractory myocardial disease with a poor prognosis. Mrs. G experienced cardiopulmonary arrest during hospitalization. She constantly struggles with uncertainty and experiences immense mental suffering from her symptoms, treatments, anxiety, and prognosis. This condition requires appropriate nursing care. Purpose: This study, which is based on Margaret Newman's theory, aims to clarify the experience of illness of Mrs. G who has dilated cardiomyopathy. Methods: This involved interpretive and dialectical praxis research. The researcher and Mrs. G formed a partnership through discussion. Hermeneutical analysis was performed on the discussion content. Results: The experience of illness of Mrs. G consisted of 6 phases: "Looking back on the shock of having an illness and receiving medical treatment", "Looking back on one's life until present", "Confusion resulting from uncertainty", "Self-insight", "Recognizing one's true feelings of wanting to live", and "Commitment and decision to live". Mrs. G could find a new self and expand her consciousness. Conclusion: Mrs. G found meaning in coping with her illness and discovered the value of living while accepting her own destiny. She connected to her own life and became more prepared to live with hope. Thus, partnership in nursing care according to Newman's theory can benefit patients with distress from dilated cardiomyopathy. This nursing support can improve patient outlook.
\end{abstract}

\section{Keywords}

Dilated Cardiomyopathy Patients, Experience of Illness, Margaret Newman Theory, Interpretive Phenomenon

\section{Introduction}

Dilated cardiomyopathy (DCM) is a progressive disease with heart failure as its 
main feature, which is prone to acute exacerbation as well as intractable heart failure, and in some patients the disease state rapidly progresses to death. It is a refractory myocardial disease with a poor prognosis. There is presently no fundamental treatment for dilated cardiomyopathy, and patients receive symptomatic treatment depending on their symptoms and condition.

The prognosis of patients with intractable heart failure is very poor, and many patients do not respond to medication. The 5-year survival rate of patients with dilated cardiomyopathy is said to be about $60 \%$ [1] [2]. Approximately $40 \%$ of the deaths are sudden deaths, mostly due to lethal ventricular arrhythmias, such as sustained ventricular tachycardia and ventricular fibrillation [3] [4].

In Japan, the brain dead organ transplant law was enacted in October 1997. In reality, there are many patients who are not able to receive a heart transplant owing to the present situation of heart transplantation and lack of experience of hospitals in Japan, and it is expected to take a long time before heart transplantation becomes a general medical treatment in Japan.

The course and prognosis of dilated cardiomyopathy are hence difficult to anticipate. Therefore, patients are constantly fighting uncertainty and feeling mental suffering from the symptoms, treatments, pain due to limitations of daily life, anxiety, and conflicts of future prospects. In particular, patients experience a large amount of anxiety and psychological burden owing to the uncertainty of the disease, such as sudden cardiac insufficiency, acute exacerbation, and refractory heart failure. From the above, it can be said that dilated cardiomyopathy is a severe diseases with an unknown cause and poor prognosis. It is also a chronically progressive disease, with an uncertain course of progression. Therefore, the mental suffering experienced by patients with dilated cardiomyopathy is thought to be large.

In the theory of "Health as Extension Consciousness", nursing theorist Newman [5] suggests that people have "the potential to establish themselves" under any circumstances. In addition, Newman states that having a disease or not having a disease is a part of a person's life process, and that through the interaction between the patient and the carer; both of them can find new meanings from their experiences, and they can continue to expand beyond their own self. Despite the fact that patients are experiencing uncertainty and mental distress, the experience that patients with dilated cardiomyopathy go through has not been fully elucidated. Therefore, it is very difficult to understand the type of assistance that is required based on the type of myocardial infarction and the type of cardiovascular disease that the patient is experiencing. It is hence important to clarify the experience of patients with enlarged cardiomyopathy so that we can provide the appropriate nursing care.

\section{Aim}

The aim of this research is to clarify the illness experience of a patient with dilated cardiomyopathy, using the theory of Margaret Newman as the theoretical foundation. 


\section{The Study}

\subsection{Research Design}

The research design of this study is interpretive and dialectical [5]. The study uses a dialectical method in which both researchers and research collaborators interact with each other through dialogue in a partner relationship, thereby giving meaning to the situation of the opponent, taking a step from their own recognition, and understanding the situation of the opponent by a dialectical process. This process is interpretive in the sense that it expands the understanding of both participants. For the interview, the design used is a semistructured interview that emphasizes dialogue.

\subsection{Data Collection}

Based on the research guidelines from Newman's theory [5] and an interview guide created by researchers, a semi-structured interview focused on dialogue was conducted. Eight interview sessions were performed, and the interview time for 1 session was 30 to 60 minutes.

\subsection{Data Analysis}

Interview data was transcribed in verbatim, and analyzed based on the interpretive and dialectic method, focusing on the experiences and lives of people with illness.

\subsection{Ethics}

This study was approved by the Ethics Committee of Tokyo Women's Medical University. This study was conducted with the approval of the ethics committee of the medical institution that collected the data. Selection of research collaborators was judged by a doctor as not to cause a load on a medical condition. I explained my research purpose and method to the research collaborators with the document and verbally. Research cooperation is based on free will and the patient was told that she can withdraw even after consenting to the research, and there is no disadvantage, personal information will be protected written consent. In the interview, the researcher guaranteed that the patient does not have to talk about anything she does not want to talk about, and the interview can be discontinued in the event of a feeling or sick physical condition during the interview, and they will not cause disadvantages. One interview was between 30 minutes and 60 minutes, and during the interviewing, I was always concerned about the burden of research collaborators, while observing my physical condition and facial expression.

\section{Case Study Introduction}

\subsection{Introduction of Mrs. G}

Mrs. G is a housewife in her 40 's living with her husband. She was naturally 
healthy, but in August 1993, heart hypertrophy was found from her electrocardiogram during her company's health examination, prompting her to consult a university hospital. Her condition was diagnosed as dilated cardiomyopathy and treatment was started. Despite the treatment, her cardiac function gradually declined and she fell into refractory heart failure. Thus, she was admitted for hospitalization for the third time.

After breakfast on hospitalization day 7, ventricular fibrillation during cardiac arrest occurred while brushing her teeth. Following resuscitation, she was admitted to the Coronary Care Unit. She received intratracheal intubation and underwent treatments such as using a ventilator to sustain her life. After overcoming the death crisis stage, she was transferred to the cardiovascular ward. However, her cardiac function deteriorated, and premature ventricular contraction and chest discomfort occurred. She stated in her physician medical record the following: "I am not ready to have a serious illness leading to death" and "there is anxiety about death and symptoms". Having read Mrs. G's medical record, the researcher thought that Mrs. G was in a state of confusion and needed a person who can stay close and provide her care. Thus, the researcher established a partnership with Mrs. G which she gladly accepted.

\subsection{Process of Partnership with Mrs. G}

Mrs. $\mathrm{G}$ had been hospitalized for the third time for acute exacerbation of heart failure caused by her familial DCM. After breakfast on hospital day 7, ventricular fibrillation occurred while she was brushing her teeth brushing, resulting in cardiopulmonary arrest. She was transferred to the Coronary Care Unit (CCU), where she received intratracheal intubation and underwent life-saving treatments such as being put on a ventilator. The patient condition improved and she moved to the cardiovascular ward. However, the patient underwent deterioration in cardiac function and general health even after the transfer, with frequent ventricular extrasystole, and she was aware of breathlessness and chest discomfort.

The medical record of the doctor stated that the patient said that she was "not prepared to have a serious illness that may lead to death", and "she has anxiety about death and her symptoms". From the words of Mrs. G the researcher felt that Mrs. G was in a state of confusion, fear, and anxiety, against "herself with a serious illness that may lead to death" and "the current state of acute exacerbation of heart failure". Therefore, the researcher thought Mrs. G would benefit from having a person to stay by her and care for her, and volunteered for a partnership. Mrs. G was happy about the partnership saying "I am not sure what will happen to me, but thank you". The researcher was deeply moved, and felt that Mrs. G's heart symptoms, physical suffering at the time of the arrhythmia, and the psychological burden accompanying it, as well as the anxiety of having a severe illness that may lead to death, had put her in a state of anxiety and confusion. In the interaction between the researcher and Mrs. G, 6 phases appeared. 


\section{Results}

Process of partnership between Mrs. G and the researcher.

Mrs. G's experience with her illness was categorized into the following 6 phases.

Phase 1: Looking back on the shock of contracting an illness and receiving medical treatment.

Mrs. G talked about how upset she was when she was hospitalized for the first time, and said that she was anxious after she got married, She describes her shock during her third hospitalization, when she experienced cardiopulmonary arrest as "Really, truly, 'wandering the edge of death', as I experienced a cardiac arrest 1 week after being hospitalized for heart failure, and everything in front of me became completely dark, and then white".

After that, "I had 2 or 3 thick cords up to the neck, and I was breathing oxygen through a gas mask, and I thought what happened, where is this?" There were more doctors around me than I have ever seen, as well as all of my family members, and thought "I must be in a very bad state". I felt extremely hopeless just after waking up in the CCU. She told also talked about the shock of her illness as "It is very painful breathing is difficult, but slowly understanding my situation was also painful". "I felt like I was losing my mind".

"It was very difficult, and I felt that I was both physically and mentally ill."

In this phase, the patient reflected back on when her symptoms of heart failure worsened, and talked about her thoughts about her own suffering and her own "close encounter with death", and being in a critical situation. Therefore in this phase, she was reflecting on her tragic experience by remembering her own feelings and emotions at that time.

Phase 2: Looking back on one's life until the present.

Mrs. G commented that meeting her husband was the biggest turning point in her life, as

"I met my husband early in college when I was in the third year, and looking back on her life up to now, said," I think thing have gone quite well, and I have lived without any inconveniences so far, I tend to ask people for assistance, I think I am quite dependent on others, I think I have been that way from a very young age. She also looked back on how her disease had been affecting her life, as follows. "Even after being diagnosed. I wanted to spend as normal a life as possible, so I went on holiday, and was able to do activities as long as they didn't involve intense exercise. Although there were some restrictions, it was not so inconvenient, not like I couldn't do many things, so it just felt slightly inconvenient, I guess I hadn't taken my diagnosis so seriously, because I didn't have many symptoms", sickness in life I talked about herself and looked back on herself.

Phase 3: Confusion resulting from an uncertain.

Mrs. G said, "After my heart stopped once, it's been weak, but it started mov- 
ing again, I am suffering, but I am not sure if saying I wasn't is a good idea. There is a conflict within me about ultimately requesting a transplant, like "what does it mean to live", But I can't yet feel that, "If my heart stops, I am ready to die".

She also appeared confused, such as "I have this strong desire to live, like an attachment to life". I think I am attached to the thought of being alive. It's not like I feel self-hate for thinking like this, but, I don't know. She was confused.

Mrs. G was entering phase 2, phase 3, and pattern recognition.

Phase 4: Self-insight.

Mrs. G next reached the phase of self-insight, such as, "when I was in paint, it was really, really, really, difficult and I really thought that I was going to die, and I never thought that I had such a strong hold on life. Even now, I still do not know what will happen in the future, but my heart started to move like usual again, and I think that the fact that it started moving is saying you should experience more hardships, or something like that". "It wasn't like I was living in a hurry, but I wanted to find the answer". "But now, I strongly feel that I need to first accept what is in front of me, and do what I can do".

Phase 5: Recognizing one's true feelings of wanting to live.

In response to such self-insight, Mrs. G then reached phase 5.

She stated her realization of her will to live, as "Although my illness cannot be cured, if someone said", There is just one way you can get better, "I would actually like to take that choice, a heart transplant, even if the chances of actually getting better are low".

Phase 6: Commitment and decision to live.

In the final phase, Mrs. G stated her commitment to live, as "Now that I have become like this, I feel that I have to think about a new future, my heart stopped and I collapsed, but I was rescued. But I was in terrible pain afterwards, and I may face even more pain. But I think this is probably a chance I was given to think and to overcome this situation, that it is a gift. I want to think about many things and overcome a lot of hardships through this".

"I feel that my way of life, since I have experienced something different to everyone, my way of life should have meaning to the people around me, and I shouldn't just live meaninglessly".

\section{Discussion}

Mrs. G had a cardiopulmonary arrest accompanied with acute exacerbation symptoms, and was resuscitated and forced to recuperate in the CCU experiencing physical discomfort and treatment, anxiety of her prognosis, and a psychological burden from a sense of fear. Moreover, she avoided directly facing her state of confusion and pain, and she could not put her feelings of helplessness into words, and kept them deep in her heart. However, Mrs. G got a nurse as a partner who faced her suffering and distress with her, and through repeated conversations, she looked back on her life and experience of medical care, and 
reconfirmed them. As a result, by putting meaning into the experiences of her life and medical care up to now, she was able to accept the person she is as she is with honest feelings, and to enter deeply into her inner self, Through self-insight, she was able to directly face her feeling of distress, anxiety, and fear, and was able to express her anxiety and fear regarding her prognosis which had been confined within herself. By going through such a series of processes, Mrs. G now thinks that although things remain chaotic and us difficult, she has found a new way of living.

Newman [5] states that, a time of confusion is the time when people make new choices and overcome situations that are considered impossible. This is the time that people learn new rules. Therefore, through experiencing confusion, anxiety, and many problems, Mrs. G went on to grow as a human being. This is in agreement with the results of previous research [6]-[17]. In the process of Mrs. G's growth as a human being from her suffering, she went deeper into her own inner self and through self-insight; she realized that the body "has nothing to do with the essence of herself, even if it is eroded by sickness". From this awareness, she established a new rule that "I have found the meaning of living as a person with an illness, and to be myself is the value of my life”. For Mrs. G, her new way of life meant to live with hope in connecting while accepting her situation, which is having an intractable disease with a poor prognosis. In adapting to having an illness with an uncertainty prognosis, she decided to seriously face the challenge of living while struggling and suffering. Mrs. G's decision to live with her disease led to an expansion of her consciousness as to how to live.

Newman said, "As experiences of life-threatening diseases and destructive events can lead to transcendence and become a turning point for the evolution of consciousness", and that "Releasing ourselves and going through a painful experience puts importance on oneself and lets oneself expand his/her consciousness". It is important. Reed [18] states in the self-transcendental theory that self-transcendence is to transcend oneself to an even higher level than oneself who has been growing. From that, the expansion of Mrs. G's consciousness of self-growth and evolution can be explained by the self-transcendental theory of Newman [5] as well as that of Reed [18]. Frankl [19] [20] states that "When people face desperate conditions, they will try to find the meaning of their life". Instead of living in the same way as before the illness, and by not valuing life based on the fact that she had been living her life as she planned, Mrs. G thought deeply about what was actually important to her, and that even under conditions of despair she could live a valuable life. Thus awareness also led to her expansion of consciousness.

The extension of consciousness of Mrs. G is that by accepting the fact that she has a disease with a poor and uncertain prognosis, 3 aspects, namely "live being herself despite her illness", "live as a human being", and "being prepared to continue life" lead her towards living as herself according to her own values, which was a step toward living life with an illness, which will become an index of life. 


\section{Implications in Nursing}

Based on the Newman's theory, the process of partnership in which a nurse and Mrs. Gtalked to each other, resulted in an expansion of consciousness, and lead to the realization that even though she has an illness, her essence as a person has not changed. The fact that the patient used Newman's theory to face her situation of having an illness, her suffering, anxiety, and fear lead to the patient finding a new way of living. It is also important to identify when to partner with a patient whose mind is in a state of chaos, for his/her maximum expansion of consciousness by his/her own power. Therefore, utilization of Newman's theory appears to be effective for patients with dilated cardiomyopathy.

\section{Study Limitations and Future Prospects}

This study was based on the illness experience of one dilated cardiomyopathy patient. The partnership between the author and Mrs. G, who shared her experiences as a dilated cardiomyopathy patient, provided valuable suggestions regarding nursing care. In the future, the author plans to increase the number of research subjects who have the same condition as Mrs. G, and improve nursing practice according to the present findings.

\section{Conclusion}

This study was aimed to clarify the experience of illness of Mrs. G, who was a patient with dilated cardiomyopathy, based on Margaret Newman's theory. Through repeated discussions with the nurse who formed a partnership with her, who listened closely to her suffering, Mrs. G was able to reach deep into her inner self and gain self-insight. She realized that even if her body was damaged by sickness, her essence as a person had not changed. In addition, she was able to create a new rule that even if she had an illness; to be herself and living her life were what was important. Mrs. G further underwent expansion of consciousness, which was accepting her destiny as a patient who had a refractory disease with a poor prognosis, and she became determined to live with the hope of continuing her life. This suggests that partnership in nursing care in accordance with Newman's theory can benefit patients suffering from distress caused by dilated cardiomyopathy and can play an important role in improving their outlook in life. This study demonstrated that nursing support in the form of a partnership with patients (e.g., Mrs. G) was important for providing optimal care to more of these patients.

\section{Acknowledgements}

The author is grateful to the doctors and nurses of the Department of Cardiovascular Medicine at Tokyo Women's Medical University Hospital. The author would also like to thank Mrs. G for sharing her valuable experiences with the author. 


\section{Conflicts of Interest}

The author declares no conflicts of interest regarding the publication of this paper.

\section{References}

[1] Matsuda, N. (1997) Medical Treatment and Prognosis of Dilated Cardiomyopathy. HEART Nursing, 10, 1128-1134. (In Japanese)

[2] Okamoto, H. (2008) Steady Progress in Basic and Clinical Practice, Cardiomyopathy, Life Prognosis of Dilated Cardiomyopathy. Biomedicine \& Therapeutics, 42, 90-91. (In Japanese)

[3] Kasanuki, H. and Mastuzaki, M. (2005) Heart Failure and Arrhythmia Improving Life Prognosis of Chronic Heart Failure. 1st Edition, Kounando, Tokyo, 8-102. (In Japanese)

[4] Mastuzaki, M. (2008) ABC of New Diagnosis and Treatment, Cardiomyopathy. Saishinigakusya, Tokyo, 100-170. (In Japanese)

[5] Newman, M. (1994) Health as Expanding Consciousness. 2nd Edition, National League for Nursing Press, New York.

[6] Moch, S.D. (1990) Health within the Experience of Breast Cancer. Journal of Advanced Nursing, 15, 1426-1435. https://doi.org/10.1111/j.1365-2648.1990.tb01785.x

[7] Endo, E. (1996) Pattern Recognition as a Nursing Intervention with Adults Cancer. University of Minnesota, Minneapolis and Saint Paul, 156-156.

[8] Utley, R. (1997) Life Patterns of Older Women Who Have Survived Breast Cancer. Wayne State University, Detroit, 167.

[9] Endo, E. (1998) Pattern Recognition as a Nursing Intervention with Japanese Women Ovarian Cancer. Advances in Nursing Science, 20, 49-61. https://doi.org/10.1097/00012272-199806000-00006

[10] Newman, M. and Moch, S.D. (1999) Life Patterns of Persons with Coronary Heart Disease. Nursing Science Quarterly, 4, 161-167. https://doi.org/10.1177/089431849100400408

[11] Newman, M. (1999) The Rhythm of Relating in a Paradigm of Wholeness Image. Journal of Nursing Scholarship, 31, 227-230. https://doi.org/10.1111/j.1547-5069.1999.tb00485.x

[12] Inagaki, J. and Endo, E. (2000) The Process of Pattern Recognition with Laryngectomies Distressed Long Term. Oncology Nursing Forum, 14, 25-35.

[13] Takagi, M. and Endo, E. (2005) The Process of Caring Partnership between an Elderly Patient with Cancer and a Nurse Based on Margaret Newman's Theory of Health. Oncology Nursing Forum, 19, 59-67.

[14] Awa, M. and Yamashita, M. (2008) Persons' Experience of HIV/AIDS in Japan Application of Margaret Newman's Theory. International Nursing Review, 55, 454-461. https://doi.org/10.1111/j.1466-7657.2008.00658.x

[15] Thornihill, K., Lyons, A.C. and Nouwen, A. (2008) Experiences of Living with Congestive Heart Failure a Qualitative Study. British Journal of Health Psychology, 1381, 155-175. https://doi.org/10.1348/135910706X170983

[16] Welstand, J., Carson, A. and Rutherford, P. (2009) Living with Heart Failure: An Integrative Review. International Journal of Nursing Studies, 46, 1374-1385. https://doi.org/10.1016/j.ijnurstu.2009.03.009

[17] Nagai, T. and Endo, E. (2009) Nursing Support for Early Adult Male Outpatients 
after Bone Marrow Transplantation with a Focus on Changes in Their Experience of Illness as They Continue to Visit Hospital in a Suffering Situation. Oncology Nursing Forum, 23, 21-30.

[18] Reed, P.G. (1991) Toward a Nursing Theory of Self-Transcendence; Deductive Reformulation Using Developmental Theories. Advances in Nursing Science, 13, 64-77. https://doi.org/10.1097/00012272-199106000-00008

[19] Frankl, V.E. (1967) Psychotherapy and Existentialism: Selected Papers on Logotherapy. Touchstone/Simon \& Schuster, New York.

[20] Frankl, V.E. (1984) Man's Search for Meaning: An Introduction to Logotherapy. 3rd Edition, Simon \& Schuster, New York. 